\title{
Vaginal Fornix
}

National Cancer Institute

\section{Source}

National Cancer Institute. Vaginal Fornix. NCI Thesaurus. Code C33848.

Any one of the four small recessed areas (anterior, posterior, and two lateral) that are formed between the marg in of the cervix and the vag inal wall. 